\title{
Evaluation of student's competencies on Social Medicine internship with the Objective Structured Clinical Examination method
}

\author{
Aouatef MAHFOUDH KRAIEM ${ }^{1}$, Charfeddine AMRI ${ }^{1}$, Sana El MHAMDI ${ }^{2}$, Asma \\ BOUSRIHA $^{2}$, Nidhal HAJ SALEM ${ }^{3}$, Taoufik KHALFALLAH ${ }^{1}$
}

\section{ARTICLE}

INFO

Article History:

Received 09.03.2017

Received in revised form

25.05.2017

Accepted

Available online 01.07.2017

\section{ABSTRACT}

The aim of the current study is to evaluate OSCE (Objective Structured Clinical Examination) stations elaborated to asses competencies of external students on the 5th year of Social Medicine internship at the Faculty of Medicine of Monastir, in Tunisia, carried out over a year. The total number of OSCE stations was 32 with an average of $5.3 \pm 2.3$ stations per session, each station lasting five minutes. More than half of OSCE stations were a clinical vignette type $(68.7 \%)$, followed by photo-type stations in 8 cases $(25 \%)$. The total number of tasks required was 76. The number of stations about a single task was $18.75 \%$. More than two-thirds of tasks involved competencies of cognitive level type III (72.1\%). The number of elements per correction grid varied between 4 and 10 with an average of $6.44 \pm 1.8$ elements. At the end of the different examination sessions, the success rate was low (1519 / 30) for $61 \%$ of learners with a discrimination index -0.41 and a difficulty index of tests $66 \%$. These results attest the feasibility of OSCE stations for evaluation of skills in medical specialty. However, a regular and more thorough evaluation of this method is necessary in order to promote skills of future general practitioner.

(C) 2017 IJERE. All rights reserved

\section{Keywords:}

Students, internship, techniques, educational

\section{INTRODUCTION}

Every profession is organized around a global corpus of knowledge, know-how, practical applications and rules that require special training for individuals involved. In medical field, clinical competence is a very important concept (Baig L, 2012; Watson R, 2002) and closely related to the quality of care provided to patients (Valloze J, 2009). The

\footnotetext{
${ }^{1}$ Corresponding e-mail:mahfoudhaouatef@gmail.com

Department of Occupational Medicine ${ }^{1}$,Faculty of Medicine of Monastir, University of Monastir

Department of Community Medicine ${ }^{2}$, Faculty of Medicine of Monastir, University of Monastir

Department of Legal Medicine ${ }^{3}$, Faculty of Medicine of Monastir, University of Monastir
} 
construction of clinical competence is carried out through the training course through a didactic program and is eventually continued in the workplace. Hospital internships represent a pivotal stage for students in learning technical gestures and acquiring clinical medical skills. Assessment of this clinical competence is an essential step in the learning process for both the learner and the teacher. In fact, OSCE is one of excellent ways used to evaluate and validate clinical knowledge and skills acquired by students. Since the OSCE formula was described by Harden in 1975, it has been a subject of many studies and has been widely adopted by educational institutions and evaluation organizations with important issues. During an OSCE, apprentice must perform a variety of clinical tasks in a simulated clinical setting, while being assessed by examiners using standardized assessment tools. (Harden RM et Gleeson FA, 1975).

To assess postdoctoral competencies of 24 neonatal candidates in Toronto, Jefferies et al have used OSCE and retained that it is a valid method to concretely evaluate the various roles of experts involved in each role-play; based on scales of competencies targeted. (Jefferies et al., 2007)

In addition, O'Sullivan recommended using OSCE to measure effectively interpersonal skills among multidisciplinary practitioners in dealing with complex situations with communication barriers. (O'Sullivan, et al., 2008)

This new form of teaching is strongly encouraged by the National End of Life Residency Education project. Physicians and patients sometimes lack skills to approach end-of-life care. Learning about how to address these issues by exploring values and beliefs can be experienced through the use of ECOS. (Gilman Aronson \& Kirby, 2002)

In Tunisia and as part of a pedagogical reform, the Faculty of Medicine of Monastir has introduced the OSCE as a method of assessing clinical skills of students since 2012. In this study, we report the experience of community medicine, occupational medicine and legal medicine at the Faculty of Medicine of Monastir in assessing skills of external trainees in the 5th year of medicine by OSCE stations.

The objectives of this study were to evaluate through a qualitative, quantitative and docimological study, stations of Objective Structured Clinical Examination method elaborated to evaluate competencies of external students on Social Medicine internshipand to propose recommendations for improvement of these tests.

\section{METHOD}

We analyzed OSCE stations developed for the end-of-course examination dedicated to the external trainees of the 5 th year of medicine who spent the course of social medicine during the academic year 2015-2016. Data were collected using a pre-established grid inspired from the rules for development of OSCE stations in the literature. OSCE stations were analyzed quantitatively and qualitatively. In order to evaluate results of the OSCE during each session, we consulted the archives of the education department at the Faculty of Medicine of Monastir, Tunisia. 
- Quantitative approach: The quantitative evaluation involved the determination of number of stations, number of students evaluated per group and the overall average of OSCEs.

- Qualitative approach: The qualitative analysis of OSCE stations focused on specific indicators of OSCE and on the validity characteristics of these stations. We studied the number of tasks per station, the cognitive level concerned by the items (level I: knowledge, memory, level II: comprehension, interpretation, level III: application, solution), type of station (Clinical vignette, simulated patient, station office, biological examination, radiography, video, mannequin). Also, the subtype of OSCE stations were specified (interrogation type stations, physical examination stations, type "interpretation", stations of the type to be held, stations of "gesture" type and stations of "Education" type)

- The evaluation of the correction grid was based on number of elements, observable and dichotomous elements, total notation and notation per element.

\section{Docimology evaluation:}

- $\quad$ Success rate: defined by the percentage of students who had an overall average $\geq 15 / 30$. Three levels of success were defined:

- High level of success: represented by the rate of students who had an overall average $\geq 25 / 30$.

- Average success rate: the student rate has had an overall average of [20 / 30-25 / 30[.

- Low level of success: represented by the rate of the students who had an overall average between $[15$ / 30-20 / 30 [.

Ideally, a high success rate significates that teaching is good. In turn, a high success rate may reflect a too easy station and irrelevant. A low rate would reflect an unacceptable level of difficulty or ambiguity in the question, or an issue unrelated to the training given.

A more sophisticated indicator has been described in docimology, it is the index of discrimination. This is the number that determines the "ability" of a question to differentiate between the "Forts" group (F) and the "Weak" group (W). The percentage of individuals who successfully completed the item in each of the groups $F$ and $W$ was determined.

\section{Discrimination Index (Ind. Dis) $=(2(F-f)) / N$}

The difference between the 2 ratios (\%) is the index of discrimination. This index varies between -1 and +1 . If a test consists on questions with high discrimination indices, it ensures a discriminatory classification of students according to their level of performance. It does not benefit the "weak" in relation to the "Forts". In other words, it helps to recognize the best students. 
Classification of the discrimination index:

- 0.35 and up: excellent question

- 0.25 - 0.34: good question

- 0.15 -0.24: marginal issue to be revised

- <0.15: wrong question, to re-examine, to eliminate. (Quinton A, 2016)

Index of difficulty: This index is expressed with two decimal places (example: 0.64) and ranges from 0 to $100 \%$. Some call it the Facility or Success Index. A question with an index between 30 and $70 \%$ is acceptable. It increases the chances of increasing the discrimination index.

\section{Data Analyses}

For data analyses, SPSS 13.0 Statistical Package Program was used. The results were expressed by the mean for quantitative variables and percentages for qualitative variables.

\section{FINDINGS}

I- Quantitative approach:

The number of OSCE stations per training session was 32 with an average of $5.3 \pm 2.3$ stations. During study period, 229 learners took the internship course in social medicine, divided into six groups with an average number of $38.16 \pm 2.5$ students.

The overall average of OSCE was $19.46 \pm 2$ out of 30 . This average varied by specialty. It was $5.37 \pm 1.5$ out of 10 for forensic medicine, $7.3 \pm 3.75$ out of 10 for community medicine and $6.5 \pm 3$ out of 10 for occupational medicine.

More than half of OSCE stations developed were clinical vignette type $(68.7 \%)$, followed by photo-type stations in 8 cases $(25 \%)$. (Figure 1 ) 


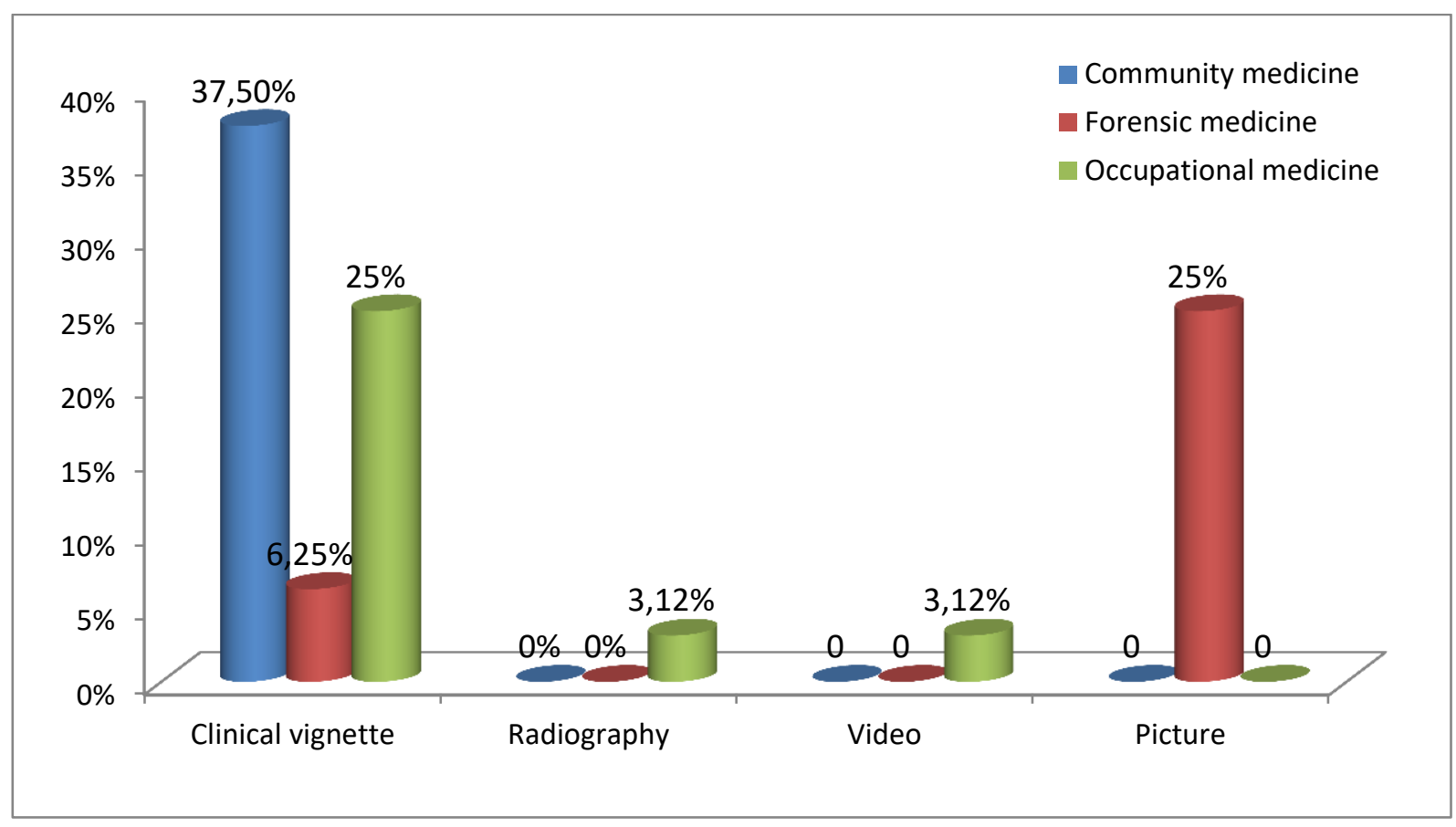

Figure 1: Distribution of OSCE stations according to the type of equipment used

The number of tasks requested per OSCE station varied from 1 to 4 with an average of $4 \pm 2.8$. The number of stations carrying a single task was $18.75 \%$.

Students were asked to identify anamnestic elements in 6 Community Medicine stations, 4 Legal Medicine stations and on Occupational Medicine station. This type of task involved $7.8 \%$ of OSCE stations. The learners were asked to describe a lesional assessment in 8 stations of Legal Medicine and three stations of Occupational Medicine. The description of physical injuries accounted for $14.5 \%$ of the total targets.

Students had to interpret a complementary examination in 18 objectives (32.7\%): Legal Medicine 4 objectives, Community Medicine 4 objectives and Work Medicine 10 objectives.

The students were evaluated in 15 stations on convenient practices, 8 of which were community medicine and 2 were from Legal Medicine. The theoretical gestural skills of the outsiders were evaluated in 4 stations: 3 of Community Medicine and one Occupational Medicine station and Health education was evaluated in 15 stations, including 7 on Community Medicine and 4 on Occupational Medicine.

According to the taxonomic classification of Bloom, more than two thirds of tasks involved competencies of the cognitive level type II and III (72.1\%).

In our study, all the items developed assessed competencies in the field of knowledge and know-how. For the three specialties, a total of five minutes was allocated for each OSCE station. 
The evaluation of the correction grid revealed that the number of elements per grid was between 4 and 10 with an average of $6.44 \pm 1.8$ elements (Figure 2) whose were all distinct and dichotomous. They were written in a clear, unambiguous way in all stations.

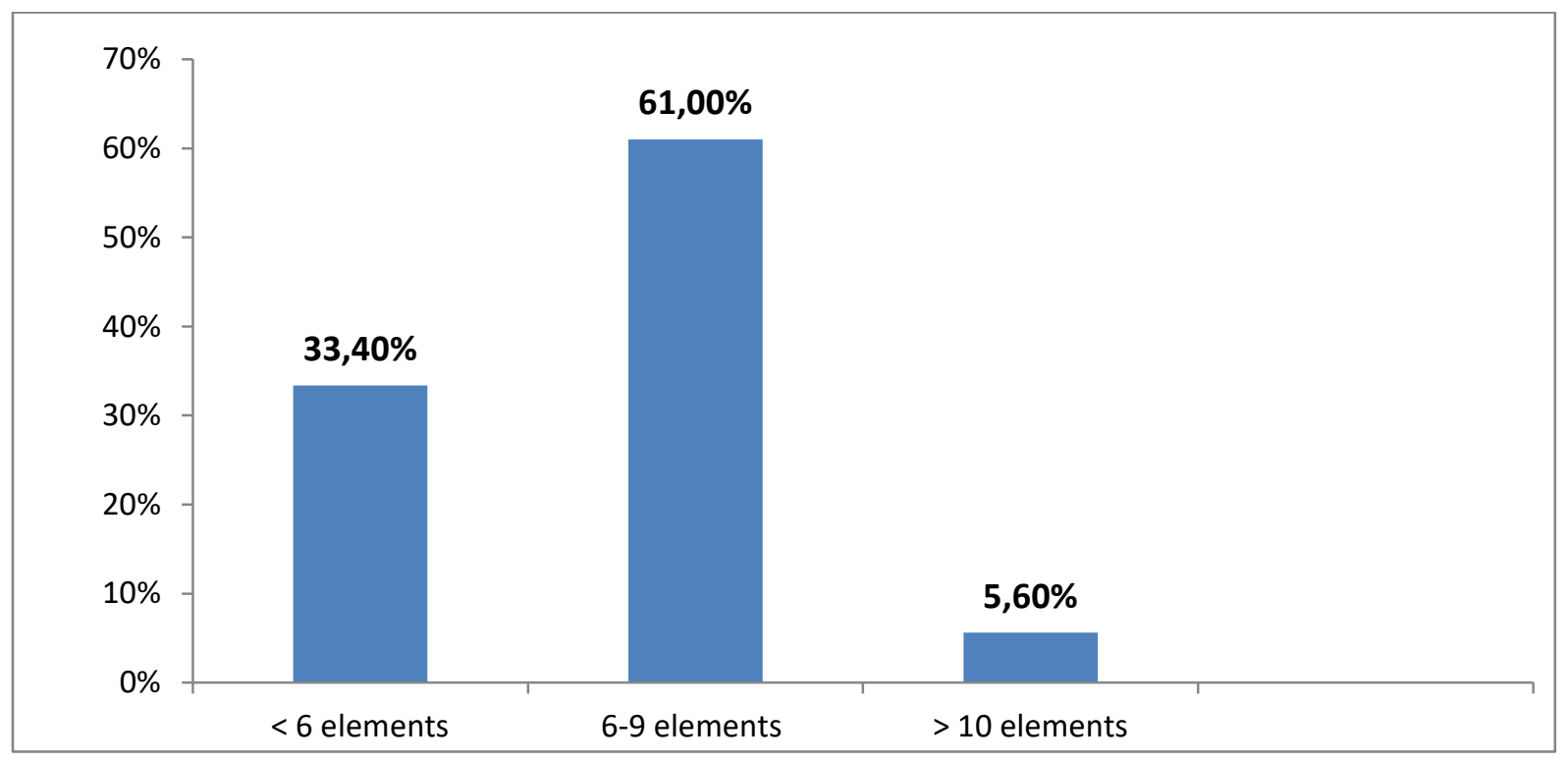

Figure 2: Distribution of OSCE stations according to the number of elements per correction grid.

In all three specialties, the total score of the OSCE stations was 10. The rating of each grid element varied between 0 and 2. The weighting was 1 in 25 stations (78\%).

The internship completion rate was $98.6 \%$. Three students were absent on the day of the exam. The success rate was low (15-20/30) for 61\% of learners. (Figure 3)

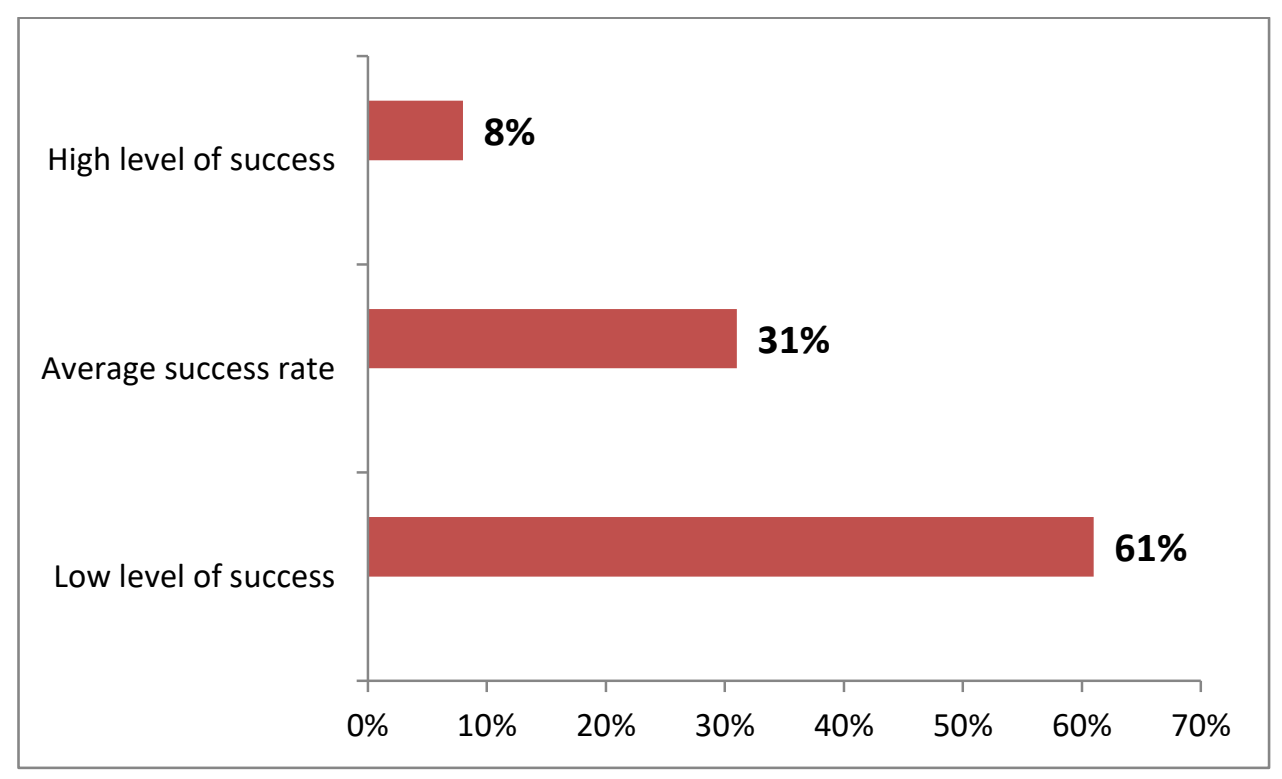

Figure 3: Distribution of external students by level of achievement. 
In our study, the index of discrimination of OSCE stations was -0.41 with a difficulty index of $66 \%$, considered acceptable.

\section{RESULT, DISCUSSION, AND SUGGESTIONS}

Hospitals stage in medical studies represents an essential period for students to learning technical gestures and for acquisition clinical medical skills. In our faculty, external trainees were previously assessed in different ways (oral test, clinical case, patients). These evaluations included a written examination and a modest number of patients to be examined by the future physician. These methods were widely criticized (Harden RM and Gleeson FA, 1997; Barman A, 2005; Matsell DG, 1991, Smith LJ, 1984). In fact, clinical presentation of patients may be not representative of routine medical practice (Smith LJ, 1984). Similarly, a common divergence in ratings within the same team of evaluators was criticized for these assessment methods (Barman A, 2005; Matsell DG, 1991; Smith LJ, 1984), hence the value of using a more objective way of assessing clinical skills of students, the example of the OSCE (Harden RM, 1975; Conseilmédical du Canada 2012). One of strengths of OSCE is to assess not only skills of interrogation and physical examination, but also the ability of candidates to integrate and organize these skills into a clinical reasoning process leading to decision-making diagnostics and therapeutics. Moreover, in the evaluation of gestures and attitudes, direct observation of the student in action is generally a more valid method than relying solely on the result or the product of this action. (Schoonheim-Klein M, 2008; Schoonheim-Klein M, 2005)

Although the OSCE assessment is a reference method to evaluate clinical competence at all levels of the medical curriculum, it is an experiment recently used in the Faculty of Medicine of Monastir, notably for the assessment of clinical competences of graduate trainees. This work presents a retrospective evaluation of OSCE stations proposed during the end-of-placement examination sessions intended for the 5th year interns who spent the course of the Social Medicine during the academic year 2015-2016.

During the study period and for six end-of-training sessions, 32 OSCE stations were developed, with an average of $5.3 \pm 2.3$ stations per session and duration of five minutes each. These data approximate those described in the literature. The original format of OSCE described by Harden et al. (1975) involved a series of 16-20 stations with duration of 5 minutes spaced 30 seconds apart to allow candidates to pass to the next station and to the evaluation team to record the comments (Harden RM, 1975). Matsel et al evaluated the validity and reliability of OSCE in a pediatric clinical course using 10 stations to evaluate 77 students (Matsell DG, 1991). Similarly, Sibert L et al., to assess the feasibility and acceptability of OSCE for Urology interns, developed 5 stations for 20 students (Sibert, 2000). In a sampling of 7 quasi-experimental OSCE searches, the number of stations varied from 8 to 38 stations and the duration of each station varied from 4 to 15 minutes. (Cohen R, 1990; Petrussa ER 1990)

As mentioned by Harden (1988), OSCE is recognized as a flexible and adaptable examination (Harden RM, 1988). It is in this context that several training programs, particularly in the health sector, have adapted the OSCE according to their pedagogical 
needs. However, several authors recommend including a large number of short stations in the OSCE circuits for approximately 5 minutes in order to maintain an acceptable level of validity and fidelity. (Bartfay WJ, 2004; Schuwirth LWT and van der Vleuten CPM, 2003)

In our survey, it appears that the OSCE is well appreciated by teachers as long as it has been adopted throughout the academic year. This perception was better objectified in the study of Sibert L. et al, who reported a good appreciation of the OSCE method for assessing skills of interns in urology (Sibert L 2000). However, the OSCE, according to some authors, did not get the favor of external and it is in connection with the superficial and artificial nature of the examination. They also denounce its lack of transparency as a result of a lack of feedback. (Remmen R, 2000; Van der Hem-Stokross HH, 2003; Van der Vleuten C, 2000)

In our survey, most of performed tasks were in the domain of knowledge (description of anamnestic elements, description of a physical lesion, and interpretation of a complementary examination). On the other hand, the evaluation of clinical competences, mobilized by the know-how and the knowledge to be were lightly represented. Only $39.4 \%$ of objectives have solicited clinical reasoning process of the students through the conduct type stations and interpretation of para-clinical examinations, which is explained by the absence of simulated patient type station. In our work, more than half of the OSCE stations developed were about clinical vignette type $(68.7 \%)$, followed by photo-type stations $(25 \%)$ and video-type stations in $3.12 \%$ of cases. These stations, also called dry stations, allow the evaluation of certain basic skills, such as interpretation of para clinical examination and description of physical lesions. In fact, the design of an OSCE station as described by Harden et al. (1975), was based on two types of stations, stations with a standardized patient where the candidates had to perform a clinical procedure. Then there will be other stations where a written task was requested in connection with the previous station in the form of questions to be answered or there will be imaging examinations or laboratory reports to be interpreted (Harden RM, 1975). This type of interaction provides the learner with the most genuine learning and evaluation experience possible and is, in a way, a transition zone into the real clinical environment by giving them the opportunity to practice their competences. (Barrows HS, 1993)

For logistical and financial reasons, the recruitment of simulated or standardized patients is not common practice in our faculty. OSCEs often take place at the faculty and sometimes in hospital departments, what is in relation to the absence of premises dedicated to OSCE. On the other hand, the number and availability of observers was insufficient for observing each station. Our faculty is committed to solving this problem and collaborating with the simulation center to provide the necessary equipment for the stations with technical gestures.

The flexible format of the OSCE (number of stations, length of stations, parallel circuit, proportions of stimulus stations / question stations / station break) will make it easier to carry out this type of test while respecting the "gold standard" of an OSCE station.

In conjunction with the OSCE scoring instruments, it is recommended to use a hybrid scoring strategy that combines an observation grid with an evaluation scale or an evaluation scale which permits a professional judgment of the evaluator. (Joly, 2013) 
The number of elements required in the correction grid depends on the case and the time allocated. Generally, for a station of short duration (5 to 7 minutes), the number of elements can vary from 8 to 25 elements. In our work, the number of elements per correction grid was 6 on average with extremes ranging from 3 to 15; considered to be compatible with the tasks required. In our study, the weighting of the elements of correction grid varied from 0 to 2 . The grade awarded varied most often by 1 or 0 for the elements of correction grids (78\% of stations). This approach is the simplest and makes it possible to reconcile the scoring tools with automated scoring processes. (Joly L, 2013)

Evaluation by OSCE may be associated with a significant variability in the results of the stations and a discrepancy between these results and the expectations of authors, which may affect the validity of this measuring instrument. As a consequence, a docimological evaluation of sessions is necessary to remedy these shortcomings and allow a more rational view on the developed stations and the results of these tests. The success rate of an OSCE test varies according among studies. Paul Grand' M. et al., in a study on the competency assessment of family medicine residents between 1990 and 1991, reported a success rate between 91 and 100\% (Paul Grand' M, 1992). This is closer to our results in witch $98.6 \%$ passed the end-of-course examination evaluated by OSCE with a slight disparity between specialties.

These results may reflect a good external coaching. In fact, the supervision of external students is one of the fundamental concerns of our faculty. A training committee was created and among these roles was to evaluate the internship book and discuss the internship objectives for each specialty. An internship manager is appointed to prepare in advance the program of supervision of the externals and ensure the smooth running of the course. Similarly, the supervision of external staff is done by university teachers. This is not the case for some academic institutions. After having surveyed more than 880 external, the team of the University of Antwerp makes a poor assessment of the quality of teaching supervision during the day school. In this study, the supervision of the outsiders was mainly based on junior residents (Remmen R, 2000).

Dolmans et al. confirmed that the quality of supervision is the most influential parameter in the assessment of student's courses (Van der Vleuten C, 2000; Barrows HS, 1993; Joly L, 2013; Paul Grand' M 1992; Daelmans HEM, 2004; Dolmans DHJM, 2002; Dolmans DHJM, 2002). This parameter would even be superior to the quality of the clinical exposure. Quality supervision would easily compensate limited or less diversified exposure. The clinical teacher assumes a very influential role in learning of the external and in the development of his professional identity. (Langevin S, 2007)

In our current practice, the success or failure score of a clinical test, evaluated by OSCE, is calculated arbitrarily relative to the mean. Such notation seems to be debatable in the literature. Indeed, the establishment of the pass mark is necessary. By defining the minimum acceptable performance, it provides a basis for decision-making thereafter and ensures quality control. However, there is no ideal or standard method. (livingstone $S$ and Zieky M, 1982; Newble D, 1994)

In literature, Angoff method is the most widely used (Livingstone $\mathrm{S}$ and Zieky $\mathrm{M}$, 1982; Morrison H, 1996). Each board member determines individually for each item of 
each question the expected percentage of "boundary candidates" or minimally competent who should answer correctly. A consensus must then be obtained by all members of the jury on this percentage. The product of this percentage and the weight given to the item gives the minimum score expected for this item. The pass mark for the exam is obtained by summing the expected scores for each item.

The criterion-based approach, for example, judges the performance of the student, not in relation to that of his peers, but in relation to a pre-established external standard, it makes it possible to clarify the level of competence in absolute value, which seems more satisfactory to test clinical competence. (Newble D, 1994; Turnbull J, 1989)

For some authors, the establishment of the pass mark by a criterion-based approach should be preferred in the absence of a need for classification and when the examination concerns a small number of candidates as is the case for end-of-training examinations. (Turnbull J, 1989)

Surely, the success rate in our study is very high. But, the breakdown of students by level of success found that $61 \%$ had a low success rate and only $8 \%$ of students had a high success rate. These results can be explained by the non-discriminatory nature of OSCE stations, consistent with a discrimination index of -0.41 . This makes difficult to classify students according to their level of performance.

In contrast, the level of difficulty of OSCE stations evaluated in our study was $66 \%$, which reflects an acceptable level of difficulty. This discrepancy in the results could be explained by the heterogeneity of success rate according to specialties (success rate in occupational medicine $=98.4 \%$, success rate in community medicine $=97.8 \%$ and the success rate in legal medicine $=84.3 \%$ ).

Despite these results, some limitations are noted. The analysis focused on a small number of stations, due to the absence of an OSCE bank and the short study duration. The evaluation of the stations was carried out by a teacher who has participated in the development of these stations, which could limit the objectivity of the analysis. However, the use of an analytical grid, based on the literature on the rules for development of OSCEs could reduce this bias.

Despite these methodological limits, our study constitutes a docimological reference to improve the OSCE for evaluation of clinical skills of external interns in Social Medicine.

The key to a successful OSCE is meticulous planning. Implementation of an OSCE Coordinating Committee for each specialty is important and the Coordinator should monitor all aspects of the review. The content of the OSCE must be determined by a committee that is properly informed of the program of study and the skills to be acquired. For a reliable assessment of clinical competence, all these components (history of the disease, physical examination, problem solving, interpretation of laboratory results, therapeutic education) must be widely represented through an adequate number of stations of sufficient duration. In order to better judge the level of knowledge, especially the know-how and skills of learners, the development of OSCE stations with standardized patients is strongly recommended. Once the examination has been completed, an evaluation of the sessions is required, in particular by establishing the pass mark, which 
allows to define the minimum acceptable level of performance and to ensure quality control of the level of competence.

\section{REFERENCES}

Baig, L., Violato, C., Crutcher, R., (2010). A construct validity study of clinical competence: a multitraitmultimethod matrix approach. The Journal of continuing education in the health professions, 30 (1): 19-25.

Barman, A., (2005). Critiques on the objective structured clinical examination. Annals Academy of Medicine Singapore, 34(8): 478-482.

Barrows, HS., (1993). An overview of the uses of standardized patients for teaching and evaluating clinical skills. AcademicMedicine, 68(6) : 443-451.

Bartfay, WJ.,Rombough, R., Howse, E. et LeBlanc, R., (2004). The OSCE approach in nursing education: Objective structured clinical examinations can be effective vehicles for nursing education and practice by promoting the mastery of clinical skills and decision-making in controlled and safe learning environments. The Canadian Nurse, 100(3): 18-25.

Cohen, R., Reznick, RK., Taylor, BR., Provan, J., et Rothman, A., (1990). Reliability and validity of the objective structured clinical examination in assessing surgical residents. Am J Surg., 160 (3): 302-305.

Daelmans, HEM.,Hoogenboom, RJI., Donker, AJM., Scherpbier, AJJA., Stehouser, CDA., Van Der Vleuten, CPM., (2004). Effectiveness of clinical rotations as a learning environment for achieving competences. Medical Teacher, 26: 305-312.

Dolmans, DHJM.,Wolfhagen, HAP., Essed, GGM., Scherbpier, AJJA., Van der Vleuten, CPM., (2002). Students' perceptions of relationship between some educational variables in the out-patient setting. Med Educ, 36: 735-741.

Dolmans, DHJM.,Wolfhagen, IHAP., Essed, GGM., Scherbpier, AJJA., Van der Vleuten, CPM., (2002). The Impacts of supervision, patient mix, and numbers of students on the effectiveness of clinical rotations. Acad Med, 77: 332-335.

Harden, RM., (1988). What is an OSCE? Medical Teacher, 10(1): 19-22.

Harden, RM., and Gleeson, FA., (1979). Assessment of clinical competence using an objective structured clinical examination. Med Educ, 13(1):41-47.

Harden, RM., et Gleeson, FA., (1979). Assessment of clinical competence using an objective structured clinical examination (OSCE). Med Educ, 13(1):41-54.

Harden, RM., Stevenson, M., Downie, WW., et Wilson, GM., (1975) Assessment of clinical competence using objective structured examination. BMJ, 1(5955): 447-451.

Jefferies, A., Simmons, B., Tabak, D., McIroy, J. H., Lee, K.-S., Roumeka, H., et al. (2007). Using an objective structured clinical examination (OSCE) to assess multiple physician competencies in postgraduate. Medical Teacher, 29, 183-191. 
Joly, L., (2013). Conception d'un examen clinique objectif structuré pour le volet pratique de l'épreuve synthèse du programme Technologie de radio-oncologie. Essai présenté à la Faculté d'éducation en vue de l'obtention du grade de Maître en enseignement (M.Éd.) Maîtrise en enseignement au collégial. savoirs.usherbrooke.ca/handle/11143/7674. Consulted 01/013/2017

Langevin, S., Hivon, R., (2007). En quoi l'externat ne s'acquitte-t-il pas adéquatement de son mandat pédagogique ? Une étude qualitative fondée sur une analyse systématique de la littérature. PédagogieMédicale, 8: 7-23.

Livingstone, S., and Zieky, M., (1982). Passing scores. A manual for setting standards of performance on educational and occupational tests. Evaluationnal Testing Services, Princeton, USA, 71p.

Matsell, DG., Wolfish, NM., et Hsu, E., (1991). Reliability and validity of the objective structured clinical examination in pediatrics. Med Educ, 25(4): 293-299.

Matsell, DG., Wolfish, NM., Hsu, E., (1991). Reliability and validity of the objective structured clinical examination in paediatrics. Med Educ, 25(4): 293-299

Morrison, H., Mc Nally, H., Wylie, C., Mc Faul, P., Thompson, W., (1996). The passing score in the objective structured clinical examination. Med Educ, 30: 345-348.

Newble, D., Dawson, B., Dauphinee, D., et al (1994). Guidelines for assessing clinical competence. Teaching and Learning in Medicine, 6: 213-220.

O'Sullivan, P., Chao, S., Russel, M., Levine, S., \& Fabiny, A. (2008). Development and implemenatation of an objective structured clinical examination to provide formative feeback on communication and interpersonal skills in geriatric training. Journal of the American Geriatrics Society, 56(9), 1730-1735.

Paul Grand', M., Lescop, J., Rainsberry, P., Carlos, A., Brailovsky, MD., (1992). Large-scale use of an objective, structured clinical examination for licensing family physicians. Canadian Medical Association Journal, 146(10): 1735-1856.

Petrussa, ER., Blackwell, TA., et Ainsworth, MA., (1990). Reliability and validity of an objective structured clinical examination for assessing the clinical performance of residents. Archives of Internai Medicine, 150 (3): 573-577.

Quinton, A., (2016). Docimologie : Epreuve, notation. D.U. de Pédagogie - Actualisation février du texte de Mai 2013 http://www.crame.u-bordeaux2.fr/

Remmen, R., Denekens, J., Scherbpier, A., Hermann, I., Van der Vleuten, C., Van Royen, P., et al., (2000). An evaluation study of the didactic quality of clerkships. Med Educ, 34: 460-464.

Schoonheim-Klein, M., Muijtjens, A., Habets, L., et al., (2008). On the reliability of a dental OSCE, using SEM: effect of different days. European journal of dental education, 12: $131-137$. 
Schoonheim-Klein, M., Walmsley, AD., Habets, L., van der Velden, U., Manogue, M., (2005). An implementation strategy for introducing an OSCE into a dental school. European journal of dental education, 9: 143-149.

Schuwirth, LWT., and van der Vleuten, CPM., (2003). The use of clinical simulations in assessment. Med Educ, 37(S1): 65-71.

Sibert, L., Paul Grand', M., Charlin, B. et Grise, Ph., (2000). Développement d'un Examen Clinique Objectif Structuré pour évaluer les compétences des internes en urologie. Pédagogie médicale, 1(1): 33-39.

Smith, LJ., Price, DA., et Houston, IB., (1984). Objective structured clinical examination compared with other forms of student assessment. Archives of Disease in Childhood, 59: 1173-1176.

Turnbull, J., (1989). What is Normative versus Criterion-referenced assessment? Medical Teacher; 11: 150-154.

Valloze, J., (2009). Competence: A concept analysis. Teaching and Learning in Nursing, $4: 115-118$

Van der Hem-Stokross, HH.,Daelmans, H., Van der Vleuten, C., Haarman, H., Scherbpier, A., (2003). A qualitative study of constructive clinical learning experiences. Med Teach, 25: 120-126.

Van der Vleuten, C., Scherbpier, A., Dolmans, D., Schuwirth, L., Verwijen, G., Wolfhagen, H., (2000). Clerkship assessment assessed. Medical Teacher, 22: 592-600.

Watson, R., Stimpson, A., Topping, A., etPorock, D., (2002). Clinical competence assessment in nursing: A systematic review of the literature. Journal of Advanced Nursing, 39(5): 421-431. 